Thorax (1952), 7, 167.

\title{
PEPTIC ULCERATION AND PERFORATION OF THE STOMACH AFTER OESOPHAGECTOMY
}

\author{
BY \\ V. S. BROOKES AND J. L. STAFFORD \\ From the Department of Surgery, Queen Elizabeth Hospital, Birmingham, and the Department of Pathology, \\ Birmingham University
}

(RECEIVED FOR PUBLICATION MARCH 5, 1952)

An unusual complication of oesophagectomy is the development of gastric ulceration, and two patients have been seen recently in which this happened. In each one the ulcer was away from the oesophago-gastric suture line, and perforation of the ulcer led to the death of the patient. In one, this complication occurred after the patient had been successfully treated for a leaking oesophago-gastric anastomosis.

\section{CASE RePORTS}

CASE 1.-A women school teacher, aged 59 years, was admitted to the Queen Elizabeth Hospital under the care of Mr. A. L. d'Abreu in August, 1950, complaining of increasing difficulty in swallowing for one year. She had lost $1 \frac{1}{2}$ st. in weight during this period. Six months before admission a cholecystectomy had been performed in another hospital, and the preliminary gastro-intestinal investigations, including barium meals, had been uniformly negative.

Oesophagoscopy on August 16, 1950, revealed a proliferating tumour almost occluding the lumen of the oesophagus at the $26 \mathrm{~cm}$. level. On August 18, 1950, oesophagectomy was performed through a left transthoracic approach. The carcinoma extended from $1 \mathrm{~cm}$. below the aortic arch for a distance of $6 \mathrm{~cm}$., and the oesophagus containing the growth was removed. The upper segment of the oesophagus was brought in front of, i.e., to the left of, the aortic arch, and a gastrooesophageal anastomosis was performed at the level of the arch. The body and fundus of the stomach were partially supported and fixed in the chest by a series of fine, interrupted thread sutures placed between the serous coat of the stomach near the greater curvature and the divided edge of the mediastinal pleura over the descending aorta. At this operation the stomach was normal throughout. Histological examination of the excised tumour revealed an extensive, ulcerated, and grossly infected squamous cell carcinoma of the oesophagus.

The immediate post-operative course was satisfactory, but on the fourth day the patient became suddenly distressed and on aspiration air and fluid were removed from the left hemithorax. Leakage from the anastomosis was diagnosed. The left hemithorax was drained and later, on August 28, the chest was reopened and the partly broken down anastomosis was repaired. At this time the body of the stomach again appeared satisfactory. Subsequently there was a further slight leak from the anastomosis, but only small amounts of the food taken by mouth leaked out through the empyema sinus. During the next six weeks the leaking anastomosis slowly sealed and the patient's condition gradually improved. At the end of this time she was taking a reasonably normal diet by mouth. On October 13, however, she suddenly collapsed and there was a violent haemorrhage from the empyema tube track coupled with a haematemesis. She died within a few minutes.

Necropsy.-Necropsy was carried out 17 hours after death. Examination of the thoracic viscera showed that the lower two-thirds of the oesophagus had been removed. A straight anastomosis made into the fundus of the stomach, after it had been mobilized through the diaphragm, had healed except for a sinus track $0.75 \mathrm{~cm}$. in diameter running laterally and obliquely from the suture line into the left pleural cavity. An empyema occupying the left base had been partially drained through a lateral incision. The sinus track and drainage area were filled with blood clot. The left lower lobe was partly collapsed, with the formation of fibrinous exudation and organizing granulation tissue resulting in almost complete obliteration of the pleural cavity. Early bronchopneumonic consolidation was present in the right lower lobe.

Surgical mobilization of the stomach through the diaphragm had caused numerous small haematomata on the serosal surface. The cardiac orifice had been sutured and the anastomotic suture line was healthy with no evidence of any residual neoplasm. The local lymph nodes were slightly enlarged, but apparently free from growth.

In the fundus of the stomach, immediately below the oesophageal anastomosis, there was a large area of chronic peptic ulceration, $2 \times 3 \mathrm{~cm}$., in the floor of which small portions of suture material were discernible amongst the granulation tissue and necrotic debris. Two small focal areas of erosion had perforated the base (Fig. 1). 


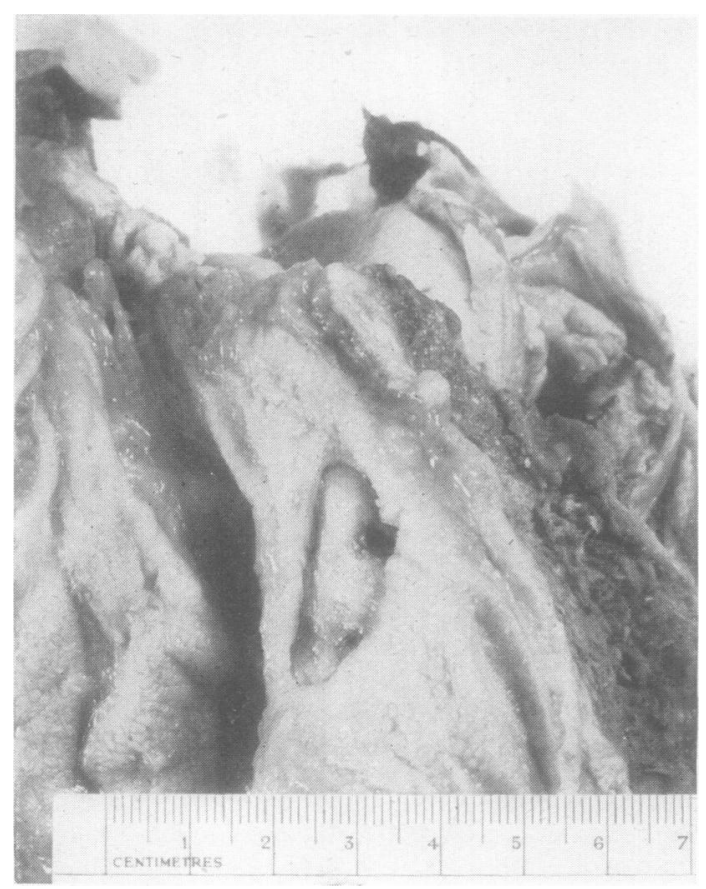

Fig. 1،

On attempting to move the stomach, which was distended with fresh blood clot, it was seen that its new position had brought the serous coat into close apposition with the anterior surface of the aortic arch. Fibrous adhesion had occurred through which the peptic ulceration had extended with ultimately direct breach of the vessel wall. Blood from the resultant haemorrhage had been forced through the sinus track, to present at the empyema drainage incision.

The heart was small, but showed no significant abnormalities except for slight valvular fibrosis and coronary sclerosis. The aortic intima was almost free from atheroma.

Histology.-Microscopical examination of the eroded gastric mucosa showed changes typical of chronic peptic ulceration (Fig. 2). No residual neoplasm could be seen, but the ulcer was centred upon small portions of nonabsorbable suture material in the middle of the base. The ulcer, with undermined edges, had penetrated the coats of the stomach wall with considerable reactive fibrosis.

The aortic adventitia was almost obliterated at this point, and the elastic laminae were fragmented. Only minimal atheromatosis was present in the adjacent intima and the two areas of erosion were through otherwise healthy tissue.

CASE 2.-A woman shopkeeper, aged 68, was admitted to the Queen Elizabeth Hospital, under the care of Mr. J. Leigh Collis, with a history of difficulty in swallowing for seven months. Investigation showed a well- differentiated squamous carcinoma $30 \mathrm{~cm}$. from $\overrightarrow{\overrightarrow{\vec{c}_{h}}}$ upper incisor teeth.

On March 18, 1950, an oesophagectomy was performed through a left thoracotomy incision. growth was below the aortic arch and was mobge. The portion of the oesophagus below the aortic aach was removed. The stomach was mobilized and brought into the chest, the cardiac orifice being closed. Oessphago-gastrostomy was performed between the funthis of the stomach and the divided end of the oesophaggis, the anastomosis being surrounded by a polythene bag. The stomach was then supported in the chest by theee sutures of non-absorbable material placed between it and the prevertebral tissues.

The post-operative course was satisfactory $u \overrightarrow{\mathbf{A}_{\mathrm{f}}} \mathrm{il}$ March 29, when the patient vomited part of her food and developed abdominal distension. The deterioration continued, and on April 3 a barium swallow and $x$-ray screening showed that there was no leak from the anastomosis, nor any obstruction. The patient diednon April 5 (the eighteenth post-operative day). A fill necropsy was refused, but the operation site was explodid. The oesophago-gastrostomy suture line was intact and viable; several inches below it there was a small frforation of the stomach at the site of one of the s $\mathrm{s}$ porting sutures. The inside of the stomach at this gite showed a small ulcer with some surrounding induratinn. Perforation had led to a leak and the formation of oan abscess in the posterior mediastinum.

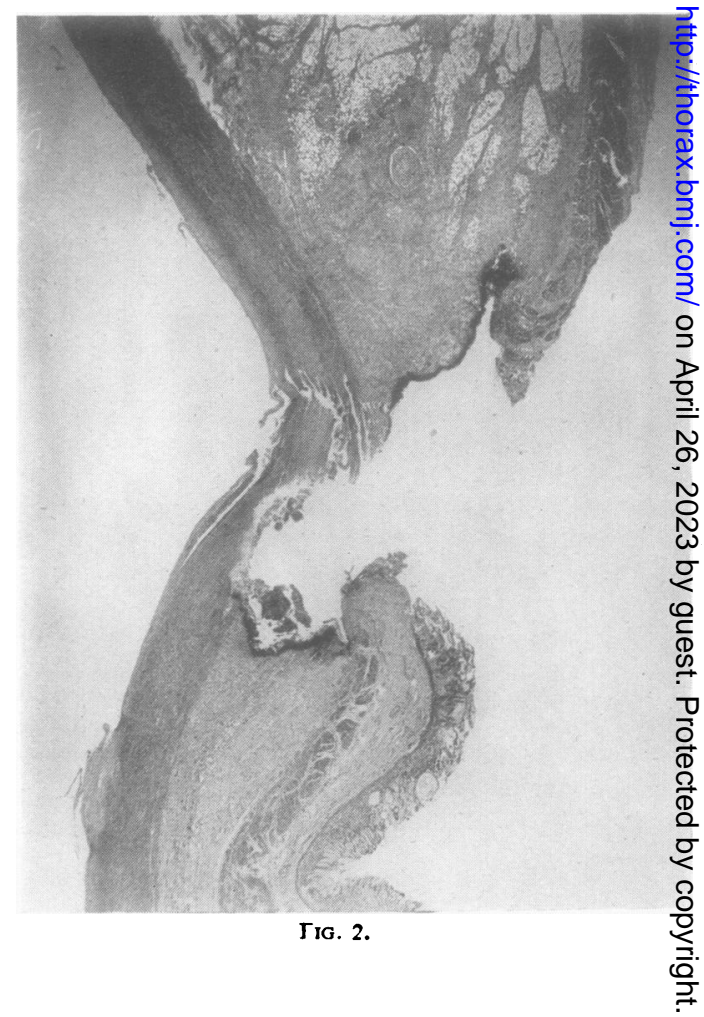




\section{Discussion}

The development of gastric ulceration and perforation after oesophagectomy has been recorded previously. Nuboer (1949a) reports two cases of chronic ulceration of the lesser curvature of the stomach, one of which developed within two weeks of the original operation, and led to the death of the patient. The other occurred after two and a half years and needed further surgery. He also reports one death from a perforation of the stomach away from the oesophageal suture line; this he attributed to avascular necrosis.

Merendino and Emerson (1950) report two fatal perforations of the stomach into the thoracic aorta following oesophagectomy. In one, a suture of the anastomotic line had been placed through the aortic intima, and led to an aorto-oesophago-gastric fistula on the twelfth day. The other suffered a leaking anastomosis on the seventeenth day with adherence to, and finally perforation into, the aorta on the eightieth day. They advised the interposition of omentum between the aorta and the suture line in order to reduce the risk of this type of fistula. Sweet (1946) advises the use of supporting sutures between the stomach and the pleura over the aorta, and the other authors have confirmed this point in the technique of the operation. Brewer (1949), describing oesophagectomy, reports that during the placing of supporting sutures in one case bleeding occurred from the aortic wall.

In the first of our two patients the gastro-aortic fistula developed well away from the suture line at a point where the stomach was stitched to the mediastinal pleura over the aorta. It would seem advisable that such sutures be placed well away from the aorta, and preferably in the prevertebral tissues of the posterior mediastinum. Each patient had developed an ulcer at a point where one of the sutures between the stomach and the mediastinal tissues had been used to fix and support the stomach in the chest, particularly with a view to lessening tension on the oesophago-gastric suture line. In each instance only four or five such sutures were used, and the tension on each may have been great enough to lead to local injury. As an alternative to anchoring sutures, many sutures placed close together would support the stomach and lessen the tension at each particular point of suture. The sutures used in both these operations were of nonabsorbable material, the use of which in gastric surgery has often in the past been blamed for the development of chronic ulceration (Rouhier, 1947; Vandecasteele and Madranges, 1949; Vergoz, Maury, and Rejet, 1941). Since most gastric surgery, however, is for chronic ulceration, the recurrence following operation is far more likely to result from fundamental causes than the use of any particular suture material.

In Nuboer's cases no mention was made of local injury as a cause of ulcer development. He (Nuboer, 1949b) later suggested that the vagotomy necessarily effected during the removal of the lower oesophagus may have been a factor in the development of the ulceration. Cases of gastric ulceration following vagotomy for duodenal ulcer have been reported by Orr and Johnson (1949, one case), Dragstedt, Camp, and Fritz (1949, two cases), and Morrissey (1950, three cases).

\section{SUMmARY}

Two cases of gastric ulceration after oesophagectomy are reported. In one, death was due to perforation of the ulcer into the aorta, and in the other to development of a posterior mediastinal abscess. Both ulcers were centred on sutures used for supporting the stomach in the chest, and some suggestions are made regarding the use of such sutures. It is also noted that the necessary division of both vagi during oesophagectomy may be of some aetiological significance.

We wish to express our gratitude to Professor F. A. R. Stammers, Mr. A. L. d'Abreu, and Mr. J. L. Collis for their permission to report these cases and their help and advice in preparing this article.

\section{REFERENCES}

Brewer, L. A. (1949). Ann. Surg., 130, 9.

Dragstedt, L. R., Camp, E. H., and Fritz, J. M. (1949). Ibid., 130, 843.

Merendino, K. A., and Emerson, E. C. (1950). J. thorac. Surg., 19. 405.

Morrissey, D. M. (1950). Brit. med. J., 2, 651.

Nuboer, J. F. (1949a). Arch. chir. neerl., 1, 14

(1949b). Acta gastro-ent. belg., 12, 380.

Orr, I. M., and Johnson, H. D. (1949). Brit. med. J., 2, 1316

Rouhier, G. (1947). Mém. Acad. Chir., Paris, 73, 239.

Sweet, R. H. (1946). Ann. Surg., 124, 653.

Vandecasteele, -., and Madranges, -. (1949). Arch. Mal. Appar. dig., 38, 1012.'

Vergoz, -., Maury, J., and Rejet, - (1941). Algérie méd. (Ed. Chir.), 45, 211. 